\title{
OPINION
}

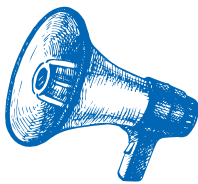

\section{Talent Search versus Talent Development}

\section{George Berzsenyi}

\section{Note: The opinions expressed here are not necessarily those of Notices.}

\section{Introductory Remarks}

The terms search and development are certainly different, and yet the concepts of talent search and talent development are often confused with each other. I did that too when I initiated the USA Mathematical Talent Search (USAMTS) thirty years ago. In the first part of the present note I will concentrate on the difference between the two concepts with the aim of pointing out that while we have the machinery for doing an excellent job of talent search at the pre-college level, we are doing poorly in the area of talent development. In the second part of this note, based on my personal experiences I will recommend a workable model for talent development.

\section{Talent Search via Mathematical Competitions}

Ever since the initiation of the Kürschák (then called Eötvös) Mathematics Competition in Hungary in 1894, mathematical competitions have been recognized as reliable methods for talent searches throughout the world. Similar nationwide competitions came into existence in other countries in the 1930s and 1940s and finally in the United States and Canada too in the 1950s. The American High School Mathematics Examination (AHSME) was started then. It soon became a valued program of the Mathematical Association of America (MAA) and eventually grew into the pyramid of competitions shown on the right.

George Berzsenyi is professor emeritus of mathematics at Rose-Hulman Institute of Technology. His email address is gberzsenyi@gmai 1 . com.

For permission to reprint this article, please contact: reprint-permi ssion aams.org.

DOI: https://dx.doi.org/10.1090/noti 1950

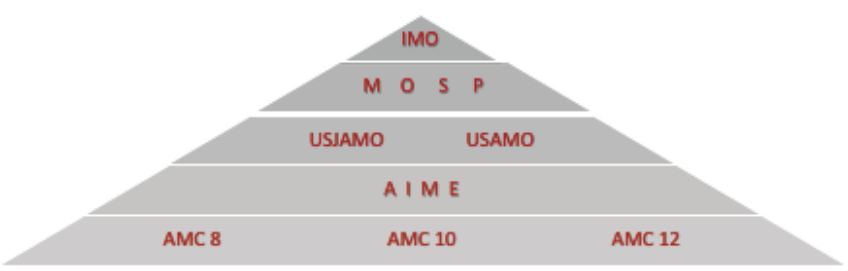

They are well-developed talent searches administered by the MAA committee on the American Mathematics Competitions (AMC) for students at the pre-college level, with the AMC 8, AMC 10, and AMC 12 being multiple choice examinations for students in grades 8 and under, 10 and under, and 12 and under, respectively. They are followed by the American Invitational Mathematics Examination (AIME), whose 15 problems have nonnegative integer answers less than 1000, and then the USA Mathematical Olympiad (USAMO) and its Junior version, in which the participants must solve six essay-type problems. Participation in each of these is based on performance in the previous competition(s), and hence to a great extent the entire process is aimed at finding about 60 students for the three-week Mathematical Olympiad Summer Program (MOSP), where six students are selected to represent the United States at the International Mathematical Olympiad (IMO).

It always bothered me to have several hundred thousand students take the AMC, learn that tens of thousands of them are talented, and then select 60 for a brief talent development program and ignore the rest, expecting them to develop their own capabilities and, if not discouraged, come back the following year to prove themselves again. 


\section{The Need forTalent Development}

Once the talents of tens of thousands of students are discovered via the $\mathrm{AMC}$, there should be a similarly nationwide program for assisting them in the development of their talents. They should be given instructions on problem solving techniques, hints on how to improve their skills, examples of exemplary solutions to problems, etc. It seems to be the moral obligation of organizations like the MAA, AMS, National Council of Teachers of Mathematics (NCTM), and others sponsoring the $\mathrm{AMC}$ to address, rather than continue to ignore, that issue. Ideally, there should be a combined effort by these three organizations to create a vehicle for the development of those students who are identified by the MAA's pyramid of competitions discussed above.

Next, I will describe my own efforts, showing that it can be done. In both cases I made use of the rich databases of the AMC by asking for and receiving the home addresses of hundreds and later thousands of students, to whom I wrote personal invitations to take part in my programs. It is incidental that I was a member of the committees in charge of the AHSME, AIME, and USAMO for 12 years, and it is also beside the point that I paid for the lists of addresses whenever I had funds to do so.

\section{The Competition Corner in the Now Defunct Mathematics Student Journal of NCTM}

When I became the editor of the Problem Section of the Mathematics Student, I was bothered by the small number of students submitting solutions to its problems. Therefore, during my three-year tenure, each year I asked the Executive Director of the MAA committee in charge of the AMC for the home addresses of those 120-150 students who made the National Honor Roll of the AHSME that year by scoring 100 or more out of 150 points. Their enthusiastic response was nearly overwhelming. To the 103 problems posed in 20 rounds (six in 1978-79 and 1979-80 and eight in 1980-81), an average of 69 students submitted solutions. I did the grading myself, providing feedback to the students and keeping up additional correspondence with many of them. It was a "labor of love."

My next opportunity for a similar program came about in 1989 when I wrote an article $e^{1}$ celebrating the 25th anniversary of the Wisconsin Talent Search in my regular "Problems, Puzzles and Paradoxes" column in Consortium, a publication of the Consortium for Mathematics and Its Applications (COMAP). The idea struck me to have a similar, but nationwide talent search and, fortunately, my colleagues at Rose-Hulman Institute of Technology (RHIT) were supportive of it.

\footnotetext{
${ }^{1}$ Twenty-five years of search, Consortium, Number 29, Spring 1989
}

\section{The USA Mathematical Talent Search (USAMTS)}

This time I asked for and received the home addresses of students who qualified for the AIME. Their number was at least 10 times as large as the number of those who made the National Honor Roll, and hence we had an average of 189 students submitting solutions to each of the 60 problems posed during the first three years of the USAMTS (five problems in each of the four rounds per year). The grading was done by a group of colleagues at RHIT.

When the grading of the AHSME became centralized in 1992 , I could specify my own cut-offs for inviting students via their home addresses, and hence, from that point on I could send invitations to about 10,000 of the highest scoring students of the AHSME. Therefore, during the next four years of the USAMTS an average of 817 students submitted solutions to each of the five problems posed in each of the four rounds per year. During those years the mathematicians of the National Security Agency (NSA) helped with the grading of the submissions. Upon my retirement, the NSA took over the program and then passed it on (with continuing financial and grading support) to the Art of Problem Solving (AoPS), which is still in charge of it.

\section{Personal Background, Motivations}

Being a native of Hungary, I grew up mathematically on Hungary's superb 125-year-old mathematics journal for high school students, often referred to as KöMaL. ${ }^{2}$ It has been my lifelong aim to transplant that publication to my adopted land, and I succeeded in doing so both with the "Competition Corner" and the USAMTS. Just like KöMaL, both were talent development programs, allowing one full month for the students to submit their solutions, training them to be punctual and professional in their submissions and thorough in the development of the solutions. Additionally, they were year-round competitions in order to encourage the students to stay with the program, hoping to instill mathematical problem solving as a lifelong intellectual habit in them. In spite of severe space limitation in the case of Mathematics Student and high postage costs for sending the problems, solutions, evaluations, and a USAMTS Newsletter in the case of the USAMTS, we managed to emulate KöMaL both times. Later the NSA replaced the newsletter with a well-developed website and the AoPS made other innovations to the USAMTS program. Unfortunately, Mathematics Student is long gone, and while the USAMTS is still alive and relatively well, it is just a very poor imitation of KöMaL.

\section{Call for Action}

Consequently, I hereby propose to the AMS, the MAA, and the NCTM, the three major organizations of teachers of

\footnotetext{
${ }^{2}$ An abbreviation for Középiskolai Matematikai és Fizikai Lapok (meaning High School Mathematics and Physics Journal), which has an informatics section in it too
} 
mathematics, to view my efforts as possible models for talent development. Create a joint mathematical publication for our talented high school students that will withstand the ravages of time just like KöMaL has for 125 years and $\mathrm{Abacus}^{3}$ is doing in its 25th year-in spite of the fact that Hungary lost two world wars, endured several revolutions, and suffered from Nazism and communism alike, as well as from harsh peace treaties.

The rich database available via the competitions under the auspices of the AMC should be utilized, rather than ignored. Back in the 1970s and 1980s, more than 400,000 students took the AHSME; now only 180,000 are registered for the AMC 10 and AMC 12 competitions combined. Could it be that they recognized that the only purpose for the pyramid of competitions is to select a team of six students for the IMO?

Let us prove to them that their accomplishments in those competitions will be rewarded by proper attention to their abilities. Let us help them to develop those abilities to the fullest via the only proven vehicle of success, a high school mathematics journal.

It should be an online publication appearing at least six times a year, with problem sets of different levels to which the students can submit solutions and accumulate the points gained for their solutions. A network of mathematicians should be charged with the grading. The solutions should be posted in a timely manner, with at least some credited to the students. There should be articles of interest to the students, instructional comments on problem solving, as well as reports on other competitions. And there should be some prizes for those who accumulate the most points for their solutions during the year. I am well aware that I am recommending a costly and elaborate effort, but I know that our talented students deserve nothing less than such a worthy investment in their, as well as in our country's, future.

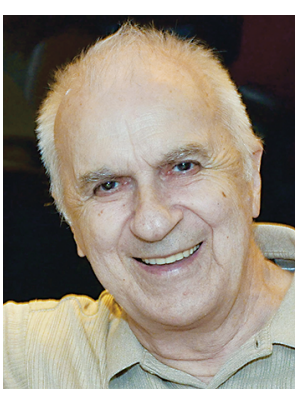

George Berzsenyi

\section{Credits}

Pyramid graphic and author photo are courtesy of the author.

\footnotetext{
${ }^{3}$ A journal initiated by Sándor Róka (and now under the auspices of the János Bolyai Mathematical Society) for students at the middle school level
}

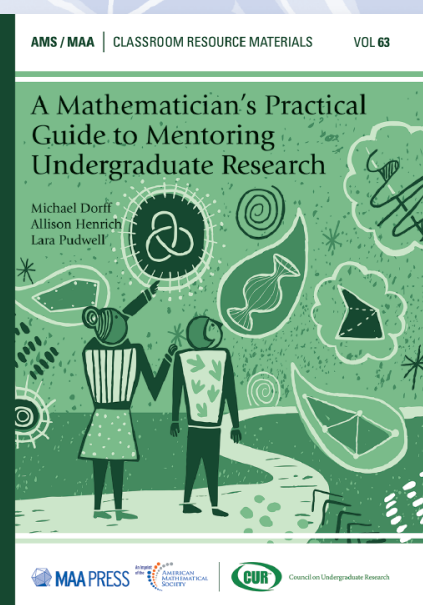

\section{A Mathematician's Practical Guide to Mentoring Undergraduate Research}

Michael Dorff, Brigham Young University, Provo, UT, Allison Henrich, Seattle University, WA, and Lara Pudwell, Valparaiso University, IN

This book is a wonderful resource for those interested in engaging undergraduates in research. The authors' extensive experience in mentoring undergraduates in research is evident throughout.

-Joseph A. Gallian, director of the University of Minnesota Duluth REU, former president of MAA, former director of MAA Project NExT

A Mathematician's Practical Guide to Mentoring Undergraduate Research is a complete how-to manual on starting an undergraduate research program. Readers will find advice on setting appropriate problems, directing student progress, managing group dynamics, obtaining external funding, publishing student results, and a myriad of other relevant issues.

Classroom Resource Materials, Volume 63; 2019; 211 pages; Softcover; ISBN: 978-1-4704-4934-6; List US\$55; AMS members US\$41.25; MAA members US\$41.25; Order code CLRM/63

Learn more at bookstore.ams.org/clrm-63 